\title{
Reflexões sobre o ensino da leitura no contexto das transformações culturais
}

\author{
Luciene de Cassia de Santana
}

Secretaria de Estado de Educação de São Paulo.

\begin{abstract}
Resumo
Este artigo tem como objetivo promover o debate sobre o processo de ensino e aprendizagem da leitura face às transformações culturais ocorridas na contemporaneidade, sobretudo no que diz respeito ao uso das novas tecnologias da informação e comunicação, à heterogeneidade cultural dos diversos atores envolvidos na esfera educacional. Para tanto, discorremos acerca dos discursos sobre leitura e suas implicações no processo de ensino/alfabetização, pois consideramos que as apropriações e as representações se constroem historicamente e, portanto, o que se ensina e como se ensina não são ações interdependentes.
\end{abstract}

Palavras chave: Transformações Culturais; Ensino de Leitura; Tecnologias da Informação e Comunicação.

\section{Abstract \\ Reflections on the teaching of reading in the context of cultural transformations}

This article aims to promote the debate about the teaching and learning process of reading in the face of the cultural transformations that occurred in the contemporary world, especially with regard to the use of new information and communication technologies, the cultural heterogeneity of the various actors involved in the educational sphere. In order to do so, we discuss discourses about reading and their implications in the teaching / literacy process, since we consider that appropriations and representations are historically constructed, and therefore what is taught and how they are taught are not interdependent actions.

Keywords: Cultural Transformations; Reading Teaching; Information and Communication Technologies.

\section{Resumen}

\section{Reflexiones sobre el enseño de la lectura en el contexto de las transformaciones culturales}

Este artículo tiene como objetivo promover el debate sobre el proceso de enseño y aprendizaje de la lectura teniendo en cuenta las transformaciones culturales que ocurrieron en la contemporaneidad, sobre todo con respecto a la utilización de las nuevas tecnologías de la información y de la comunicación, a la heterogeneidad cultural de los diversos actores envueltos en la esfera educacional Por tanto, discurrimos acerca de los discursos sobre la lectura y sus implicaciones en el proceso de enseño/alfabetización, pues consideramos que las apropiaciones y las representaciones se construyen históricamente e, por eso lo que se ensena y como se ensena no son acciones interdependientes.

Palabras clave: transformaciones culturales; enseño de lectura; tecnologías de la información y de la comunicación. 


\section{Introdução}

Transmitir a cultura para as novas gerações é um dos objetivos do ensino escolar, por isso seria difícil conceber uma escola onde o ato de ler não estivesse presente (SILVA, 2000). Por outro lado, o ensino da leitura no século XXI parece suscitar abordagens e reflexões que perpassam o redimensionamento de novos saberes, de cultura, portanto, de articulação com os contextos sociais, com as crenças, com os discursos e com as representações dos sujeitos no âmbito educacional.

Na visão de Butlen (2008), os meios clássicos de que dispõe a escola não são suficientes para a formação de leitores. Não bastam os livros didáticos, a aula com um professor e quarenta alunos cara a cara, uma vez que o professor já não é o único referente, pois na contemporaneidade o acesso à cultura escrita também ocorre por meio das ferramentas tecnológicas em distintos tempos e lugares.

Assim sendo, o ensino da leitura é um processo que se operacionaliza a partir das mudanças sociais no que se refere à apropriação da tecnologia, da heterogeneidade cultural dos sujeitos, do acesso e da distribuição dos bens culturais. Logo, a necessidade de várias lentes para compreender que o processo que envolve o ensino da leitura é multifacetado, abrangendo aspectos que vão além do que é normatizado e legitimado pela cultura escolar.

Todavia, ainda que o acesso à leitura possa se disseminar por meio das ferramentas tecnológicas na atualidade, não se pode negar que ensinar a ler continua sendo responsabilidade da instituição escolar.

Contudo, essa responsabilidade em relação a formar leitores proficientes e críticos, de disseminar a leitura como forma de emancipação dos sujeitos, lamentavelmente, a instituição escolar ainda não atingiu os seus objetivos.

Por outro lado, a expansão do mercado editorial brasileiro nas últimas décadas não deve ser desconsiderada, entretanto esse crescimento não caminhou proporcionalmente no mesmo ritmo no que diz respeito à quantidade de leitores no país, segundo pesquisas do Instituto Montenegro (2011) e Retratos de Leitura no Brasil (INSTITUTO PRÓ-LIVRO, 2010).

Importante apontar que o percentual da população alfabetizada funcionalmente foi de $61 \%$ em 2001 para 73\% em 2011, mas apenas um em cada quatro brasileiros domina plenamente as habilidades de leitura e escrita. Ainda somos um país com 13 
milhões de analfabetos.

O Instituto Paulo Montenegro e a ONG Ação Educativa, parceiros na criação e implementação do Indicador de Alfabetismo Funcional (INAF), mostram, após realização de pesquisa, que durante os últimos 10 anos houve uma redução do analfabetismo absoluto e da alfabetização rudimentar e um incremento do nível básico de habilidades de leitura e escrita. No entanto, a proporção dos que atingem um nível pleno de habilidades manteve-se praticamente inalterada, em torno de $25 \%$.

Cabe, ainda, mencionar que na $4^{\mathrm{a}}$ edição da pesquisa "Retratos de leitura no Brasil” (INSTITUTO PRÓ-LIVRO, 2015), as percepções, representações e valorização da leitura se associam, principalmente, à ideia de que a "leitura traz conhecimento”. Já representações negativas da leitura, como ocupar muito tempo, ser cansativa e obrigatória, são mencionadas em proporções significativamente inferiores às representações positivas. Quanto mais alta a renda, maior a proporção dos que declaram que gostam muito de ler em relação aos que gostam um pouco ou não gostam. Depreende-se, portanto, que as representações de leitura e os fatores socioeconômicos se engendram nesse processo, uma vez que a escolaridade e a classe social influenciam direta e indiretamente o acesso à cultura escrita em diferentes suportes, o perfil do leitor, a compra de livros, o acesso a bibliotecas e aos locais nos quais o ato de ler se operacionaliza:

Bibliotecas públicas locais são conhecidas por $55 \%$ dos entrevistados, e essa proporção aumenta na medida que aumenta o nível de escolaridade. A maior escolaridade do indivíduo, como já foi apontado, indica uma maior diversidade de materiais lidos, mas também pode influenciar no tipo de relação que ele estabelece com a leitura. Pessoas com maior nível de escolaridade tendem a ter maior habilidade leitora, o que lhes permite desenvolver outras relações com a leitura para além do seu uso instrumental (INSTITUTO PRÓ-LIVRO, 2015, p. 133).

Diante desses dados, infere-se que a participação social do indivíduo está imbricada na capacidade de apropriação do código escrito, das práticas sociais de leitura e escrita e, portanto, nas instâncias governamentais, no poder público; sobretudo a escola continua sendo a agência que pode produzir oportunidades educativas no que se refere ao processo de alfabetização, da formação de leitores, bem como da aprendizagem e do ensino desse bem simbólico.

Isto posto, é inegável que os discursos e as concepções acerca da leitura im- 
plicam no processo de alfabetização, do ensino e da aprendizagem quanto ao ato de ler nas instituições sociais e para além dela, uma vez que o que se ensina e como se ensina não são ações interdependentes.

\section{Discursos sobre leitura e suas implicações no processo de ensino}

A compreensão da realidade social perpassa os significados e as representações que se materializam nos discursos acerca de um determinado objeto. Discorrer, portanto, sobre um bem simbólico, como a leitura, pressupõe considerar os processos sociais, culturais, políticos, econômicos e cognitivos associados a muitas vertentes o impacto da difusão da escrita na sociedade, o surgimento de novas tecnologias da informação e da comunicação, as práticas de leitura, as representações e a difusão do conhecimento entre os diversos grupos sociais (GALVÃO; BATISTA, 2005).

Face a essas considerações, inúmeros são os discursos que circulam no âmbito educacional e no acadêmico acerca do que significa ler e suas respectivas implicações no processo de ensino e aprendizagem desse bem cultural, por isso, a depender do posicionamento de cada sujeito em relação aos conceitos e representações de leitura, mitos são construídos, desigualdades sociais são (re)produzidas e as oportunidades educacionais, para os grupos sociais minoritários, tendem a ser reduzidas ou ampliadas.

Para Britto (2003), o mito do sujeito leitor resulta de um tipo de discurso que, sem explicitar o que se entende por leitura e sobre as práticas sociais de leitura, desconsidera os modos de inserção dos sujeitos nas formas de cultura e, por isso, em torno da questão da leitura, vários juízos de valor são estabelecidos, tais como leituras valorizadas e não valorizadas, leituras unitárias e pluralistas, legitimadas ou não pelos diversos segmentos da sociedade e sobretudo no universo escolar.

Outra característica discursiva muito marcante diz respeito à valorização da leitura na sociedade, ou seja, pessoas que leem ficariam melhores, libertas de um estado de alienação, possibilitando seu engajamento em movimentos de solidariedade ou de transformação da sociedade. Diante dessa ideia, Britto (2003, p. 103) argumenta que, ao supervalorizar o ato de ler em si, como se fosse um comportamento sempre desejável, "perde-se completamente a crítica histórica e a percepção de que a leitura tem sido um instrumento de dominação, pois as classes dominantes sempre tiveram a escrita a seu serviço”. Em outras palavras, o discurso de uma leitura redentora não 
necessariamente encontraria correspondência entre leitura e comportamentos sempre positivos, evidenciando o que Petit (2008, p. 100) comentou: "ler não torna a pessoa virtuosa, não podemos ser ingênuos, pois sabemos o quanto a história é rica em tiranos ou perversos letrados”.

Quanto à imagem de uma leitura que possibilite viajar por mundos maravilhosos, é um discurso recorrente que se entrelaça com uma forma de ler para o entretenimento, para a diversão, e nesta perspectiva há um forte apelo de que a leitura se relaciona ao gosto. Esse discurso tem encontrado consonância em campanhas de divulgação e feira de livros, bem como em algumas práticas pedagógicas de que para formar leitores é preciso propor aos alunos leituras agradáveis e prazerosas.

Acerca desse discurso, Abreu (2004, p. 33) discorre que a distração e o passatempo não são os únicos motivos que levariam alguém a ler, pois "boa parte das pessoas lê para se instruir ou para se informar, sendo possível ler muito sem que se tire disso algum prazer”. Segundo a mesma autora, as pessoas não precisam ser convencidas quanto à importância da leitura, de que ler é um prazer; o fundamental seria realizar a difusão do acesso à educação escolar, pois há uma relação muito estrita entre leitura e escolarização, conforme resultados de várias pesquisas de leitura no Brasil (INSTITUTO PRÓ-LIVRO, 2008.), nos quais se evidenciou que a maioria dos impressos presentes nas residências dos entrevistados está fortemente vinculada à cultura escolar - livros didáticos, dicionários, livros infantis.

Britto (2003) relata que este tipo de discurso não exigiria mais que o domínio do código escrito e a ação mecânica de decodificação, uma vez que, para o pesquisador, essa prática de leitura não se diferenciaria de outras formas de consumo de cultura de massa.

Todos esses discursos em relação a uma concepção de leitura ingênua, segundo Britto (2003), mascaram a dimensão política da leitura, permitindo que qualquer leitura possa ser considerada boa, bem como desconsiderando o fato de que se leem textos e que os textos são discursos que encerram relações de poder, valores, representações de mundo e de sociedade. Isto posto, os discursos, as representações de leitura não são neutros, nem inócuos, pois engendram fatores sociais, políticos, econômicos e culturais.

Trata-se, portanto, de compreender que a leitura na sociedade é expressão de cultura e objeto de consumo, perpassando (re)produção de valores, construção de 
identidades, crenças e ideologias.

Face a essas discussões, não é possível pensar a educação sem que estejamos atentos à questão do poder (FREIRE, 1982), tendo em vista que os textos impressos, os objetos de cultura e o modo pelo qual são difundidos se aplicam a esse mesmo raciocínio (BRITTO, 2003).

E essas relações de força estão embrenhadas nas representações impostas por aqueles que "detêm o poder de classificar e de nomear e a definição, de aceitação ou de resistência que cada comunidade produz de si mesma” (CHARTIER, 1991, p. 183).

Nesses termos, é de definições, de classificações e de preceitos dogmáticos que se articula todo o processo de entendimento da leitura (GERALDI, 1993) nas esferas sociais, culminando na apropriação, nas representações dos sujeitos em relação a esse bem simbólico.

Assim sendo, os discursos sobre a leitura se entrelaçam sob uma dimensão política e por isso o leitor não é um ser que se desvincula de sua condição de classe, de sua participação social face à complexidade de acesso à cultura escrita na contemporaneidade. Portanto, "dizer sobre a leitura é referir-se a um objeto produzido nas/ pelas relações entre grupos humanos, em tempos e espaços sociais específicos, sendo, portanto, variável” (VÓVIO, 2007, p. 62).

E essa variedade se materializaria na heterogeneidade cultural dos sujeitos que leem, nos discursos e valores e nas representações no que diz respeito ao ensino da leitura nas instituições, nas políticas públicas de formação de leitores, ou seja, pensar a leitura, as práticas, de forma mais abrangente, considerando as relações sociais, a dialogicidade entre as diversas linguagens (oral, verbal, visual), na produção e circulação dos saberes, dos conhecimentos produzidos pela humanidade e que circulam nos mais variados grupos sociais.

Por outro lado, essas tessituras entre diversidade cultural e leitura podem estar a serviço de algumas interpretações equivocadas por parte das instituições e de políticas públicas, culminando na seleção do que é legítimo (ou não) ensinar.

Conforme assinalou Orlandi (2000, p. 73), “o leitor possui o direito político de acessar o conhecimento legitimado, mas todo o conhecimento, independentemente de suas raízes, deve ser valorizado”, ou seja, considerar as diferenças não significa restringir o acesso das minorias a certos materiais e a tipologias textuais. 
Assim sendo, os objetos de estudo menos “distintos" merecem a mesma atenção que os mais distintos (CHARTIER, 2007). Não se trata de substituir um objeto por outro, pois como bem argumentou Vóvio (2007):

(...) o processo de substituição pode levar à restrição de aprendizagens, de experiências, de familiaridade com práticas de uso da linguagem escrita que favoreçam a participação em sociedades mais complexas, burocratizadas e organizadas a partir de certos padrões culturais (VÓVIO, 2007, p.75)

De fato, há nas relações sociais certos embates entre as práticas culturais, produzindo discursos que ora valorizam, ora desvalorizam um determinado bem simbólico, sua circulação em diferentes campos de produção e de atuação, os modos de consumo, as apropriações e representações, e essa dicotomia se instaura devido às lentes pelas quais se observa o mundo social, as práticas humanas e seu entorno.

Portanto, sob essa perspectiva, Orlandi (2000) argumenta que a leitura não é uma questão de tudo ou nada, é uma questão de natureza, de condições, de modo de relação, de trabalho, de produção de sentidos, em uma palavra: de historicidade.

Por isso, discursos sobre leitura nos quais a presença do livro e de alguns gêneros literários são considerados os maiores representantes da cultura, dita valorizada, canônica, restrita a um público mais seleto, se alicerçam em subsídios na construção de leituras legitimadas ou não legitimadas, propiciando dicotomias a partir de classificações de "bons” e "maus leitores”, leituras autorizadas e não autorizadas nas instituições educacionais.

Para Abreu (1999), a ideia corrente do que seja ler é, em grande parte, tributária de ideias e imagens construídas no final do século XVII e ao longo do século XIX, ou seja, da associação entre leitura e enobrecimento do sujeito, em virtude da ascensão da burguesia. Mas, segundo a pesquisadora, não parece razoável pensar somente nas obras consagradas; é preciso conhecer as leituras correntes, aquelas que pessoas comuns realizam em seu cotidiano, questionar as concepções correntes de leitura e estreitar o olhar para a diversidade dos objetos e dos modos de ler.

Nessa mesma linha argumentativa, Chartier (1991, p. 178-179) defende que a "história das maneiras de ler deve identificar as disposições específicas que distinguem as comunidades de leitores, as tradições de leitura”, os usos do livro, procedimentos de 
interpretação, operacionalizando clivagens entre alfabetizados e analfabetos, os leitores hábeis e os menos hábeis, chegando, inclusive, a oralizar o que leem no intuito de compreender o texto.

Essas diferenciações acerca da cultura escrita ocorrem por conta dessas determinações que regulam as práticas, ou seja, os textos são lidos pelos leitores de acordo com os mecanismos intelectuais de que dispõem e as condições em que a escrita se materializa; logo, o que está em jogo não é classificar grupos em função apenas do que leem, do acervo que possuem, qualificando-os como bons ou maus leitores, mas principalmente entender o "processo pelo qual um texto, uma fórmula, uma norma fazem sentido para os que deles se apoderam ou os recebem” (CHARTIER, 1991, p. 181).

À luz dessa abordagem, a leitura incide sobre as apropriações, as práticas, as representações e seus recursos se correlacionam com as identidades sócio-históricas de cada comunidade de leitores (CHARTIER, 2007):

[...] é preciso situar as apropriações dentro das relações sociais que definem um mundo social particular e, ao mesmo tempo, talvez se deva retomar algo do sentido foucaultiniano deste termo, que assinala que há sempre uma vontade de monopólio, de controle, de propriedade, e que a apropriação não se dá por si mesma, mas como resultado de um conflito, de uma luta, de uma vontade em confronto com outra" (CHARTIER, 2007 p. 116-117).

Trata-se, portanto, de compreender a leitura e os leitores numa dimensão pluralista, considerando as condições de produção e de circulação nos contextos sociais.

Assim sendo, o pluralismo cultural e a heterogeneidade dos diversos grupos sociais estariam numa linha dialógica em relação às apropriações da leitura num determinado contexto, pois não se traria de estabelecer paradigmas entre leituras hegemônicas ou não hegemônicas, leitores fracos ou leitores fortes, ao contrário, abordar e problematizar a leitura à luz de lentes mais complexas - (re)construções de identidades, multiplicidade de significados culturais, condições de acesso à cultura escrita, operacionalização das representações e discursos nos diversos contextos e classes sociais sobre o ato de ler, propiciando "demonstrar que a diversidade não é contraditória com a unidade fundamental da humanidade” (CHARTIER, 2003, p. 153).

Sob essa mesma perspectiva, corroboramos o que Certeau (2003) assinala sobre as diversas práticas culturais não legitimadas na sociedade, mas que continuam a 
existir entre os mais variados grupos sociais, cumprindo uma função acerca da construção de identidades e de cultura, uma vez que:

O desígnio que um grupo elabora traduz-se imediatamente por uma constelação de referências. Elas podem existir apenas para ele, não ser reconhecidas exteriormente. Nem por isso são menos reais e indispensáveis para que haja comunicação. [...] Uma linguagem, uma vez falada [...], implica pontos de referência, fontes, uma história, uma iconografia, em suma uma articulação de "autoridades […]” (CERTEAU, 2003, p. 34, grifo nosso)

Em suma, da mesma forma que o sujeito vai se constituindo discursivamente, apreendendo as vozes sociais que lhe possibilitam conhecer a realidade em que está imerso (FIORIN, 2009), as representações e os discursos sobre a leitura suscitam diferentes compreensões e diálogos com o Outro, propiciando a construção de novas identidades e, portanto, um "leitor com a consciência mais dialógica será mais aberto a aceitar a diferença, a alteridade” (FIORIN, 2009, p. 56). Esses desdobramentos se articulam com a concepção de que os conceitos e as representações sobre língua e linguagem não são estanques, ao contrário, são construídos social e historicamente.

\section{O ensino da leitura face às mudanças sociais}

Diante do exposto, é importante assinalar que as práticas escolares e as representações sociais no âmbito educacional se vinculam direta e indiretamente com contextos sociais de todos os atores envolvidos no processo de ensino e aprendizagem, com os discursos acadêmicos e oficiais, construídos historicamente, permeando as orientações pedagógicas, os documentos norteadores, uma vez que o currículo é um lugar de disputas, de embates, ainda que represente em geral uma escola feita para as classes dominantes.

Assim, a produção de sentidos no que se refere ao ensino da leitura vai sendo determinada por uma multiplicidade de valores, de crenças, de saberes, de práticas, conforme as mudanças ocorridas historicamente na sociedade.

Portanto, à luz dessa perspectiva, para Chartier (2007), o ato de ler não se trata necessariamente de ler livros. Essas pesquisas que perguntam às pessoas se elas leem livros estão sempre ignorando que a leitura é muito mais do que ler livros. Basta ver em todos os comportamentos da sociedade que a leitura é uma prática fundamental 
e disseminada. Isto inclui a leitura dos livros, mas muita gente diz que não lê livros e de fato está lendo objetos impressos que poderiam ser considerados (jornais, revistas, revistas em quadrinhos), além dos gêneros digitais (games, blogs, redes sociais, dentre outros).

Cabe, ainda, comentar que a distribuição desigual acerca da leitura não se restringe apenas aos aspectos políticos e econômicos, mas também suscitam questionamentos e reflexões no modo como os indivíduos se apropriam das transformações ocorridas na sociedade em relação aos novos suportes e às novas tecnologias de acesso à cultura escrita. Face a essas transformações, Chartier (1999; 2003) discorre que a primeira grande revolução da história do livro foi o salto do rolo de papel para o códice, ou seja, o volume encadernado, com páginas e capítulos. Maior ainda, segundo ele, está sendo o salto para o suporte eletrônico, no qual é a mesma superfície (uma tela) que exibe todos os tipos de obra já escritos. Essa é, na opinião dele, a mais radical transformação na técnica de produção e reprodução de textos e na forma como são disponibilizados.

As mudanças de relação entre o leitor e o material escrito, determinado pela tecnologia, alteram também o próprio modo de significação - antes do códice, por exemplo, era impossível ler e escrever ao mesmo tempo porque as duas mãos estavam ocupadas em segurar e mover o rolo.

Assim, segundo o autor, nunca uma mudança de suporte como a que ocorre agora com os meios eletrônicos e digitais foi tão intensa e interferiu tanto nos mecanismos precedentes de percepção e conhecimento dos indivíduos.

E como essas mudanças estão se configurando no processo de ensino e aprendizagem da leitura, do leitor na esfera escolar na atualidade? Quais representações de leitura dialogariam ou ainda se materializariam diante desse contexto, tendo em vista que os jovens e adolescentes estão se apropriando cada vez mais cedo dos novos recursos tecnológicos? Como olhar para essa realidade e compreender o lugar e o papel dos novos suportes no que diz respeito à formação de leitores na cibercultura? ${ }^{1}$

Essas mudanças também são postuladas no próprio cenário escolar, uma vez que o leitor que na atualidade adentra o espaço educacional parece não se enquadrar

1 [...] diferenciação entre a cultura do papel e a cultura da tela, ou cibercultura, ou seja, confronto de tecnologias tipográficas e tecnologias digitais de leitura e de escrita, a partir de diferenças relativas ao espaço da escrita e aos mecanismos de produção, reprodução e difusão da escrita, segundo Soares (2002). 
nos parâmetros de ensino da leitura de décadas anteriores. Com isso queremos dizer que a imagem, a representação do leitor, o destinatário desse objeto simbólico e cultural vai sendo alterado gradualmente. A imagem de um leitor único, silencioso e imerso na sua leitura é uma figura construída historicamente, todavia cada vez mais distante da contemporaneidade. Daí a dificuldade de identificar um modelo unitário de representação do leitor e do próprio objeto leitura.

Com o fenômeno da globalização, da disseminação da cultura de massa, da indústria cultural, do surgimento de vários suportes no qual o texto se materializa, do crescimento do mercado editorial (impresso e digital), cujos objetivos transcendem o fomento e a formação de leitores críticos e proficientes, uma vez que o mercado é regido pela lei da oferta e da procura, a representação do leitor, das práticas e da leitura na instituição escolar também é consequência dos processos sociais, culturais e econômicos que caracterizam a sociedade contemporânea.

As apropriações são entendidas por Chartier (1999, p. 15) como práticas de produção de sentido, dependentes das relações entre texto, impressão e modalidades de leitura, sempre diferenciadas por determinações sociais, por isso é relevante comentar que, ainda na visão do autor, as liberdades dos leitores não são infinitas, são limitadas por convenções que regem as práticas de uma comunidade de leitores e pelas formas discursivas e materiais dos textos $\operatorname{lidos}^{2}$, por isso a autonomia do leitor depende de uma transformação das relações sociais que sobredeterminam a sua relação com os textos (CERTEAU, 2003).

Em suma, novas práticas de leitura, de letramento e de acesso à cultura escrita vão sendo redimensionadas face aos contextos sócio-político-econômicos e às mudanças culturais, e, por isso, é importante compreender que estamos diante de uma outra cultura no que diz respeito à presença das novas tecnologias, do digital, exigindo adaptação nos modos de olhar, de pensar, de aprender, de ensinar, e, portanto, de representações de leitura e de leitor que vão sendo construídas e modificadas historicamente.

2 O advento de uma nova forma de produção dos textos, determinada por alguma revolução tecnológica de grande envergadura (passagem do rolo ao códex, e do códex à tela; ou a revolução da reprodução promovida pela prensa de Gutemberg), pode condicionar poderosamente uma série de mudanças nas práticas de leitura (CHARTIER, 1999, p. 105). 


\section{A leitura e as tecnologias digitais}

As representações, os discursos e as apropriações relacionados ao processo de compreensão acerca da leitura se engendram face às mudanças sociais e culturais em uma determinada sociedade, perpassando distintos olhares de como se operacionalizam as práticas culturais nos mais variados grupos sociais.

Se, na antiguidade clássica, a leitura em voz alta era considerada a "verdadeira leitura”, conforme menciona Ferreiro (2001a), com o passar do tempo, a leitura em voz foi se impondo à medida que mudaram os dispositivos textuais (textos pontuados, com parágrafos, títulos, subtítulos, número de páginas, hipertextos, blogs, sites, etc.). É evidente que isto não ocorreu de maneira isolada, em virtude dos novos modos de produção e circulação dos textos, dos suportes, dos ambientes de leitura (universidades, escolas, bibliotecas, livrarias) na contemporaneidade.

Nesses termos, o acesso à cultura escrita e às novas tecnologias se insere nesse contexto, pois parece ser inevitável a dialogicidade do ato de ler sem pressupormos as influências e as demandas que esses instrumentos suscitam nos grupos sociais e nas instituições, sobretudo entre os nativos digitais. Para Prensky (2011), esses jovens "falam”, com naturalidade e sem “sotaque”, o idioma digital destes recursos eletrônicos como se fosse a sua própria língua materna:

Para estes jovens, as novas tecnologias digitais - computadores, telefones celulares, Sidekicks- são os principais mediadores das conexões humanos-com -humanos. Eles são completamente naturais na maneira de levar a vida, tanto nos espaços online quanto nos espaços offline. Não pensam em suas vidas híbridas como algo notável. Os Nativos Digitais não conheceram nada além de uma vida conectada a outro e ao mundo dos bits desta maneira. (PALFREY; GASSER, 2011, p. 14).

Segundo Chartier (2007, p. 53), o "mundo digital é um mundo de fragmentos descontextualizados, destacados pela vontade do leitor de qualquer totalidade (do livro, do jornal ou da revista), totalidade essa que ele não é obrigado, nem mesmo convidado, a perceber".

Por outro lado, as mudanças sociais e o acesso às novas tecnologias da informação e comunicação (TIC) acerca do redimensionamento e de diálogos com as diversas maneiras de ler não se operacionalizam sem que existam algumas adversidades no 
que diz respeito ao campo da leitura. Para Chartier (2007), isso ocorre por múltiplas razões:

[...] a presença desigual das livrarias e sua maior ou menor vulnerabilidade; a persistência ou o abandono da imprensa cotidiana; a maior ou menor democratização de acesso - econômico e cultural - aos novos suportes da escrita. Essas desigualdades no ingresso ao mundo digital, que existem tanto entre países desenvolvidos e países menos desenvolvidos, como também dentro de uma mesma sociedade, acarretam o risco de uma fratura digital e de um novo analfabetismo, mascarado por uma falsa ideia de globalização na quais técnicas e práticas estariam universalmente distribuídas. (CHARTIER, 2007, p. 29)

Em relação à presença das novas técnicas e práticas tecnológicas no cenário educacional, Coll e Monereo (2010) entendem que a internet não é apenas uma ferramenta de comunicação e de busca, processamento e transmissão de informações que oferece alguns serviços extraordinários: ela constitui, além disso, um novo e complexo espaço global para a ação social e, por extensão, para o aprendizado e para a ação educacional (CASTELLS, 2000 apud COLL; MONEREO, 2010).

Para Coll e Monereo (2010), as tecnologias da comunicação encontram seus referenciais em um ensino centrado em textos e no nascimento dos livros didáticos e do ensino a distância, por correspondência. Fala-se, hoje, da necessidade de promover uma alfabetização gráfica e visual, embora as temáticas sejam tímidas, e seu impacto, ainda limitado.

Segundo o autor, isso ocorre devido à fulgurante entrada em cena da linguagem digital e à possibilidade das diferentes tecnologias existentes convergirem em um único sistema de codificação, que, além disso, utiliza suportes mais confiáveis, mais fáceis de transportar e com maior capacidade de armazenamento.

Coll e Monereo (2010) explicitam que o bombardeio informativo e a facilidade de acesso da população às novas tecnologias não garantem que os indivíduos estejam mais e melhor informados, pois faltam critérios para selecioná-las e ratificar sua veracidade. Segundo os autores, os interesses e as finalidades daqueles que detêm o poder, bem como os meios e os instrumentos utilizados para que as informações circulem, acabam simplesmente se transformando em excesso, caos e ruído para a maioria dos cidadãos. Portanto, há um certo risco de “manipulação, de excesso de informação” e de 
intoxicação provocado por esse excesso, o que denominam de “infoxicação”. O desafio parece ser de "conseguir passar da informação para o conhecimento, o que envolve informação interiorizada e adequadamente integrada nas estruturas cognitivas do indivíduo” (ADELL, 1997 apud COLL; MONEREO, 2010, p. 23 ).

Esse suposto caos em relação às novas tecnologias da informação e da comunicação (TIC), segundo Coll e Monereo (2010), impede a dúvida e dificulta o aprendizado. A rapidez dos processos e das transformações vinculadas às TIC, assim como a multiplicidade e a heterogeneidade das diversas fontes de informação, podem propiciar a diminuição e dispersão da atenção a uma cultura de mosaico, carente de profundidade, à falta de estruturação, à superficialidade, à padronização de mensagens, à informação como espetáculo, etc. (ADELL, 1997, p. 5), contribuindo, portanto, para que as pessoas desenvolvam novas maneiras de agir, de pensar e de sentir.

Nesse sentido, outros fatores sofrem influência das TIC, como a homogeneização cultural, uma vez que a cultura entendida num sentido amplo se torna globalizada, embora nem todas as expressões e valores culturais tenham as mesmas possibilidades de difusão e circulação pelas novas redes de comunicação (COLL; MONEREO, 2010, p.24).

De fato, mesmo nas TIC, os grupos que estão no poder acabam impondo progressivamente as expressões, os discursos, os valores e sistemas culturais, em virtude de possuírem os meios e a capacidade para a difusão das tecnologias, produzindo o surgimento de novas classes sociais: os “inforricos” e os "infopobres”. Essas dicotomias se produzem porque o consumo, a criação e as dependências econômica e cultural não afetam a todos da mesma maneira, isto é, as desigualdades tecnológicas também ocorrem no nível das inovações midiáticas; e a globalização e as novas ferramentas digitais ainda não estão ao alcance de todos.

Assim, segundo Ferreiro (2006), as tecnologias se instalam em um mundo extremamente desigual, apresentando-se como “todo-poderosas” e, supostamente, iriam contribuir no sentido de minimizar, de reduzir desigualdades, mas a grande questão é não confundir o acesso à informação com o acesso às condições que podem modificar a vida das pessoas:

Antes se dizia: são subdesenvolvidos porque não sabem o suficiente (a educação como chave do conhecimento). Agora se diz: são subdesenvolvidos porque não têm acesso à informação suficiente (a informação como chave para o êxito individual e de associações empresariais seja de que tamanho for). (FERREIRO, 2006, p. 437). 
Nesses termos, portanto, "não se trata de pôr a pessoa dentro do mundo fictício gerado pelo computador, mas de integrar o computador ao nosso mundo humano" (COLL; MONEREO, 2010, p. 31). Em outras palavras, não se trata de considerar a supremacia de determinadas tecnologias em detrimento de outras como se os recursos midiáticos estivessem num campo de disputas, de concorrência desleal face aos mecanismos considerados tradicionais (livros didáticos, apostilas, revistas, jornais impressos, bibliotecas), mas de integrar oportunidades de "vislumbrar situações inusitadas e de resolver problemas; favorecer práticas interativas ancoradas no diálogo e na problematização do saber; articular os trabalhos desenvolvidos por diferentes grupos e instigar o desenvolvimento do espírito crítico”, como bem assinalou Colello (2015, p. $265)$.

Em convergência com essa mesma linha argumentativa, Ferreiro (2006, p. 442) discorre que "chegou a hora de deixar de especular sobre as novas tecnologias como uma mescla de surpresa e temor", em virtude de estarmos convivendo com elas, embora ainda seja uma convivência difícil. Por outro lado, os livros não competem com os textos eletrônicos porque cumprem outras funções - “o livro está carregado de história e a História funda nosso presente apostando no futuro”.

Quanto ao papel dos educadores nesse processo de interação entre as TIC e os alunos, as mudanças se operacionalizam a partir da identificação de um novo fenômeno - início de uma crise em um mundo conectado pelas telas do computador. Em outras palavras, a imagem de um professor protagonista acerca da transmissão de informação, de troca entre seus alunos e guardião do currículo começa a ser modificada.

Para Colello (2015, p. 259, grifo nosso), “criou-se uma situação na qual o aluno parece 'saber mais', ou 'ter um olhar mais atualizado' que o professor. O perigo dessa constatação é tomá-la com uma verdade definitiva sem considerar o contraponto do papel docente nesse novo contexto”.

Não incorporar esses recursos tecnológicos no processo de compreensão, apropriação e alfabetização acerca da leitura nas mais variadas instituições sociais na atualidade é o mesmo que autodeclarar-se “analfabeto digital” ou ainda ser considerado resistente às mudanças sociais e culturais, o que no entendimento de Ferreiro (2006) seria o mesmo que considerar a existência de uma patologia nesse cenário.

Diante disso, parece inevitável que o professor abandone gradativamente o papel de transmissor de informação, substituindo-o pelo de orientador e guia na rea- 
lização de projetos e mediador de debates e discussões (COLL; MONEREO, 2010, p. $31)$.

Todavia, segundo esses autores, dificilmente a escola e os atores que permeiam o processo educacional (docentes e gestores) farão uso das TIC para que os alunos participem de fóruns de discussões, trabalhando de maneira colaborativa, ou contrastem informações sobre os mais diversos temas; ao contrário, provavelmente usarão as tecnologias apenas para complementar as aulas expositivas com leituras e exercícios.

Nesse sentido, podemos afirmar que a tecnologia não está a serviço de (re)dimensionar novos olhares e concepções no que diz respeito à incorporação dessas ferramentas no processo educativo, mas que, "em nome do progresso, a cultura estabelecida luta sempre para forçar os novos meios a fazerem o trabalho dos antigos” (REGGINI, 2008 apud COLL; MONEREO, 2010, p. 34) .

Isto posto, os autores defendem a necessidade de analisar as mudanças que podem ocorrer na esfera educacional, sobretudo acerca do uso das TIC por parte dos alunos e professores. Dito de outra maneira, como os discursos, as representações sobre o ensino, as práticas, os processos e os resultados passam a operar no contexto das inovações tecnológicas no âmbito educacional. Segundo Colello (2015), as TIC:

[...] emergem com euforia em projetos alternativos ou em escolas que fazem do seu uso a grande propaganda do sistema, como se isso, por si só, pudesse garantir a qualidade do ensino. Muitas vezes, a idealização da modernidade leva a crer que a incorporação de equipamentos eletrônicos pela escola pode se constituir como solução para os problemas educacionais (COLELLO, 2015, p. 263).

Para Ferreiro (2006), um dos discursos mais latentes acerca da incorporação das tecnologias no que diz respeito à leitura relaciona-se à ideia da liberdade para os textos e para o leitor. Os textos circulam sem os suportes materiais que, tradicionalmente, lhes davam corpo, forma e substância, portanto, o leitor estaria livre das ordens impostas pela tecnologia precedente, ou seja, não está obrigado a folhear páginas numa sequência linear, podendo justapor, compor e saltar páginas de um texto a outro sem a necessidade de deslocar-se fisicamente; tudo isso a partir de um simples click do mouse.

Na era digital, os textos são objetos abertos, em constante mobilidade, sem 
garantias de que possamos encontrá-los aonde o vimos anteriormente e, nesse sentido, há outras demandas para o leitor. Para Ferreiro (2001b, p. 427), no espaço da internet há somente duas opções - "confiar em sites cuja seriedade é anterior à internet ou construir novos índices de confiabilidade”. Portanto, o leitor ganha liberdade, mas segundo a mesma autora, deve aprender a selecionar com critérios, com rigor.

Esse contexto nos leva a identificar duas modalidades de leitura - a leitura recreativa (menos trivial) e a leitura de estudo. Quanto à primeira, a pesquisadora comenta que há uma considerável quantidade de distrações, dentro e fora da esfera doméstica, que competem com o livro (televisão, dispositivos eletrônicos). Com isso, os livros não fazem parte do conjunto de objetos de consumo dos jovens, pois estes leem outras coisas (às vezes até de forma fragmentada), o que está em outros suportes. $\mathrm{Na}$ segunda tipologia, as leituras de estudo exigem do leitor um compromisso a longo prazo com o texto, esforço de atenção e memória, isto é, uma leitura continuada, que requer, em muitos casos, o silêncio e a solidão, termos que, no mundo contemporâneo, são vistos como “perigos a serem evitados” (FERREIRO, 2001a, p. 430).

Assim sendo, trata-se de (re)dimensionar qual seria a importância e o papel dessas novas tecnologias no processo de alfabetização, do ensino da leitura e da escrita, não somente nos aspectos metodológicos, mas também na resolução de problemas, na aquisição de competências e habilidades acerca da formação de leitores. Um desafio, sem dúvida.

\section{Referências}

ABREU, M. Leitura, história e história da leitura. Campinas, SP: Mercado de Letras; 1999.

. Os números da cultura. In: RIBEIRO, V. M. (Org.). Letramento no Brasil: reflexões a partir do Inaf 2011. São Paulo: Global, 2004. p. 89-113.

ADELL, J. Tendencias en educación en la sociedad de lás tecnologias de la información. EDUTEC, 7, 1997. Disponível em: http://www.edutec.es/revista/index.php/ edutec-e/article/view/570/299>. Acesso em: 22 jul. 2018.

BRITTO, L. P. L. Contra o consenso: cultura escrita, educação e participação. Campinas: Mercado de Letras, 2003. 
BUTLEN, M. Os desafios na formação de leitores polivalentes. O Papel do Alfabetizador, v. 4, n. 15, 2008. Disponível em: <https://goo.gl/sB9lgw>. Acesso em: 2 jul. 2018.

CASTELLS, M. A Sociedade em Rede: a era da informação: economia, sociedade e cultura. São Paulo: Paz e Terra, 2000.

CERTEAU, M. A cultura no plural. 3. ed. Campinas: Papirus, 2003

CHARTIER, A.-M. Práticas de leitura e escrita. Belo Horizonte: Autêntica, 2007.

CHARTIER, R. A aventura do livro: do leitor ao navegador, conversações com Jean Lebrun. São Paulo: UNESP, 1999.

. História cultural: entre práticas e representações. Rio de Janeiro: Bertrand, 2003.

. Práticas da leitura. São Paulo: Estação Liberdade, 1991.

COLELLO, S. M. G. A escola e as condições de produção textual:

conteúdos, formas e relações. 2015. 495f. Tese (Livre Docência em Educação) — Universidade de São Paulo, São Paulo, 2015.

COLL, C.; MONEREO, C. Educação e aprendizagem no século XXI. In: COLL, C.; MONEREO, C. (Orgs.). Psicologia da educação virtual: aprender e ensinar com as tecnologias da informação e da comunicação. Porto Alegre: Artmed, 2010. p. 15-46.

FERREIRO, E. "A revolução informática e os processos de leitura e de escrita” In: PÉREZ, F. C.; GARCÍA, J. R. (Orgs.) Ensinar ou aprender a ler e escrever? Porto Alegre: Artmed, 2001a, p. 157-164.

FERREIRO, E. O ingresso na escrita e nas culturas do escrito: seleção de textos de pesquisa. São Paulo: Cortez, 2001 b.

. O momento atual é interessante porque põe a escola em crise. Nova Escola, Out. 2006. Disponível em <https://novaescola.org.br/conteudo/238/emilia-ferreiro-omomento-atual-e-interessante-porque-poe-a-escola-em-crise $>$. Acesso em: 30 mar. 2018.

FIORIN, J. Leituras e dialogismo. In: ZILBERMAN, R.; RÖSING, T. M. (Orgs.). Escola e leitura: velha crise, novas alternativas. São Paulo: Global, ALB, 2009. p. 41-59. . Pedagogia do Oprimido. Rio de Janeiro: Paz e Terra, 1982. 
GAlVÃO, A. M. O.; BATISTA, A. A. G. (Orgs.). Leitura: práticas, impressos, letramentos. Belo Horizonte: CEALE, Autêntica, 2005.

GERALDI, J. W. Portos de passagem. São Paulo: Martins Fontes, 1993.

INSTITUTO PAULO MONTENEGRO. Indicador de Alfabetismo Funcional. 201 1. Disponível em: <https://drive.google.com/file/d/OB5WoZxXFQTCRWE5UY2FiMzFhZEk/view>.Acesso em: 21 fev. 2018.

INSTITUTO PRÓ-LIVRO. Pesquisa Retratos de Leitura no Brasil. São Paulo, 2008. Disponível em: <http://www.snel.org.br/wp-content/uploads/2012/08/pesquisa_habito_de_leitura_2008.pdf>. Acesso em: 10 fev. 2018.

Pesquisa Retratos de Leitura no Brasil. São Paulo, 2015. Disponível em: <http://prolivro.org.br/home/images/2016/Pesquisa_Retratos_da_Leitura_no_Brasil_-_2015.pdf>.Acesso em 02.02.2018.

MONEREO, C.; POZO, J. I. “O aluno em ambientes virtuais” In: COLL, C.; MONEREO, C. (Orgs.). Psicologia da educação virtual: aprender e ensinar com as tecnologias da informação e da comunicação. Porto Alegre: Artmed, 2010, p. 97-117.

ORLANDI, E. Discurso e leitura. São Paulo: Cortez, 2000.

PALFREY, J. ; GASSER, U. Nascidos na era digital: entendendo a primeira geração de nativos digitais. Porto Alegre: Artmed, 2011.

PETIT, M. Os jovens e a leitura. São Paulo: Editora 34, 2008.

PRENSKY, M. Nativos Digitais, Imigrantes Digitais. De On the Horizon (NCB University Press), v. 9, no. 5, out. 2001. Disponível em: <http://www.colegiongeracao. com.br/novageracao/2 intencoes/nativos.pdf>. Acesso em: 26 jul. 2018.

SILVA, E. T. O ato de ler: fundamentos psicológicos para uma nova pedagogia da leitura. São Paulo: Cortez, 2000.

SOARES, M. Novas práticas de leitura e escrita: letramento na cibercultura. Educação e Sociedade, v. 23, n. 81, p. 143-160, dez. 2002. Disponível em: <https://www.cedes. unicamp.br/>.Acesso em: 26 jul. 2018.

VÓVIO, C. L. Entre discursos: sentidos, práticas e identidades leitoras de alfabetizadores de jovens e adultos. 2007. 294f. Tese (Doutorado) — Universidade Estadual de Campinas, Instituto de Estudos da Linguagem, Campinas, 2007. 
Submissão: 27-02-2018

Aceite: 07-07-2018 